\title{
Psicologia e ciências humanas \\ O diálogo entre a Psicologia da Paz e o relacionamento interpessoal: aspectos teóricos e empíricos
}

\author{
Alvany Maria dos Santos Santiago \\ Agnaldo Garcia
}

\section{SciELO Books / SciELO Livros / SciELO Libros}

SANTIAGO, A.M.S., and GARCIA, A. O diálogo entre a Psicologia da Paz e o relacionamento interpessoal: aspectos teóricos e empíricos. In: SANTIAGO, A.M.S., and FONSÊCA, A.L.B., comp. Psicologia e suas interfaces: estudos interdisciplinares [online]. Salvador: EDUFBA, 2016, pp. 15-60. ISBN 978-85-232-2007-5. https://doi.org/10.7476/9788523220075.0002.

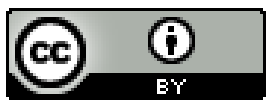

All the contents of this work, except where otherwise noted, is licensed under a Creative Commons Attribution 4.0 International license.

Todo o conteúdo deste trabalho, exceto quando houver ressalva, é publicado sob a licença Creative Commons Atribição $\underline{4.0}$. 
PSICOLOGIA E CIÊNCIAS HUMANAS 


\section{O diálogo entre a Psicologia da Paz e o relacionamento interpessoal: aspectos teóricos e empíricos ${ }^{1}$}

Alvany Maria dos Santos Santiago, Agnaldo Garcia

\section{Introdução}

A relevância dos relacionamentos para a qualidade de vida das pessoas, sejam eles no âmbito familiar, organizacional ou internacional, vem sendo discutida em alguns estudos. (GARCIA, 2005; DAVEL; VERGARA, 2001; MIRANDA, 2009) Não obstante a inconteste importância desses elos, verifica-se na literatura, assim como no cotidiano, uma tendência à associação do termo relacionamento prioritariamente à sua dimensão conflitiva. Em outra direção, a pesquisa ora apresentada trata a questão dos relacionamentos e conflitos de acordo com a abordagem da promoção da paz, com base nos estudos do relacionamento interpessoal (HINDE, 1997) e da Psicologia da Paz (CHRISTIE

1 Resultados parciais desta pesquisa foram apresentados nas International Peace Research Association Global Conferences (IPRA), realizadas em Sidney, Austrália, em 2010, e Mie City, Japão, em 2012. 
et al., 2008; GALTUNG, 1969), considerando os diferentes níveis de complexidade. Dois aspectos a serem aqui ressaltados são tanto a Psicologia da Paz que, no âmbito da intervenção, apresenta como foco central à administração de conflitos de forma não violenta, quanto os estudos sobre relacionamentos interpessoais de Hinde (1997), que são passíveis de serem aplicados nos campos de estudos da Psicologia Organizacional e da Administração, considerando que o grande desafio de ambos os campos de saberes "[...] é lidar adequadamente com pessoas e seus relacionamentos nas organizações”. (VENTORINI, GARCIA, 2004, p. 119)

Esse estudo tem por objetivo investigar o papel de diferentes níveis de relacionamento (interpessoal, intergrupal e internacional) para a promoção da paz mundial de acordo com a visão de participantes do Servas Internacional. O Servas Internacional pode ser considerado como uma Organização Não Governamental (ONG), movimento para a paz ou rede mundial de amizade e de hospitalidade, a depender de como está organizada nos mais de 125 países onde atua. Ademais, esse estudo apresenta como pontos centrais:

1) o emprego de duas perspectivas teóricas, relacionamento interpessoal e Psicologia da Paz;

2) a centralidade da ideia de níveis de complexidade, comum às duas perspectivas, e;

3) a análise de um organização/movimento social e seu possível papel para a paz.

A realização da presente pesquisa justificou-se por sua relevância científica e social. A importância de estudar o relacionamento interpessoal para a construção da paz mundial possibilita a geração de conhecimentos de aspectos que poderão promover ações que privilegiem esses dois pontos, podendo influenciar o comportamento das pessoas bem como aumentar a percepção de aspectos limitadores a uma sociedade de paz. 
Do ponto de vista científico, há poucos estudos sobre o papel do relacionamento interpessoal para a promoção da paz internacional, apesar das relações interpessoais serem um nível de relacionamento reconhecido nesse sentido. Soma-se ainda, ao ponto de vista social, a importância de estudar a promoção da cultura da paz, assim como a propagação dos valores ligados a ambas, além da importância de ações para elevação do capital social, melhoria do bem estar e qualidade de vida e seus efeitos no desenvolvimento sustentável.

Ademais, a divulgação dos estudos sobre relacionamentos e da Psicologia da Paz pode contribuir para o desenvolvimento de intervenções práticas baseadas nos valores ligados à cultura e à promoção da paz no âmbito familiar, organizacional, comunitário e internacional. (CHRISTIE et al., 2008)

Temos uma cultura voltada para a valorização do mais forte, do dominador e da manutenção do poder, e apresentamos uma tendência a resolver os conflitos de forma violenta. (CHRISTIE et al., 2008) A História, pelo menos na educação básica, tem focalizado principalmente nos relatos das guerras e conquistas e defendido os valores militares. (HINDE; PARRY, 1989; OLIVEIRA, 2007) A Organização Mundial da Saúde (OMS) em seu primeiro Relatório Mundial sobre Violência e Saúde de 2002 informa que um grande número de pessoas perde a vida em virtude das guerras. Especificamente no século XX, o quantitativo estimado é de 191 milhões de mortes causadas pelas guerras e conflitos.

Bobbio (2003) pontua que as mortes causadas pelas ações de guerra poderiam ser evitadas, já que contra as provocadas pelas epidemias, inundações, erupções de vulcões e outras catástrofes naturais que matam milhões de pessoas não se pode fazer muita coisa. Cohrs e Boehnke (2008) citam dados do Heldelberg Institute for International Conflict Research, de 2007, e afirmam que, depois de 1945, o número de conflitos violentos no mundo, especialmente os de média intensidade, nos quais o uso da força é utilizado em alguns incidentes, tem aumentado, consideravelmente. Acrescentam que 
esses conflitos ocorrem nos espaços geográficos interno aos países e internacionalmente, sendo, muitos deles, de origem religiosa. Bobbio (2003) ainda ressalta o alto custo das guerras e da indústria da guerra mesmo nos tempos considerados de paz e sinaliza que os recursos utilizados nessa indústria poderiam ser investidos, por exemplo, em ações ligadas à garantia dos direitos humanos. O autor discute quais seriam os melhores caminhos a serem trilhados pelos movimentos pacifistas em relação a uma atividade política que propicie o diálogo entre as mais diferentes tendências e que tenha como grande objetivo a eliminação das guerras internas e entre as nações.

Não apenas a historiografia, mas a mídia tende a pautar expressivamente temas ligados à violência. Os acontecimentos violentos tomam a atenção da mídia, e, conforme Santana (2004, p. 2), as seguintes perguntas têm sido discutidas em diversos eventos de comunicação:

A exploração obsessiva da violência pela mídia seria apenas uma resposta ao público, para satisfazer a sua curiosidade mórbida e saciá-lo no seu apetite pelo trágico? No caso do Brasil, vive-se hoje um 'estado de violência' ou o que existe é uma super exploração de fatos violentos?

Nesse sentido, pesquisas têm demonstrado a relação entre a exposição de crianças à violência exibida pela mídia e o desenvolvimento de comportamento agressivo. (NJAINE; MINAYO, 2004; SCHRAIBER; D’OLIVEIRA; COUTO, 2006)

Além de a mídia focalizar os aspectos violentos, pode-se afirmar que também contribui para a propagação de comportamentos preconceituosos. Sodré, Soares e Kosovski (1994) citam Baratta (1993) quando afirmam que prevalece na opinião pública os crimes ligados às classes sociais mais populares, protagonizados pelos "criminosos" e seus estereótipos. Por exemplo, em virtude de alguns fatores como a menor privacidade no ambiente doméstico, os casos de lesões corporais e violência sexual ganham mais visibilidade nos bairros mais pobres. A mídia atua na condução dos fatos, enfocando alguns fenômenos criminais e contribui para criar o estereótipo do "criminoso" 
que geralmente é retratado associado à questão de território (residente em bairros pobres) e raça (negro ou pardo). Baratta (1993 apud SODRÉ; SOARES; KOSOVSKI, 1994) acrescenta ainda que poucos têm noção que os delitos que mais lesam a sociedade são aqueles cometidos por indivíduos das classes sociais mais altas, os chamados "crimes do colarinho branco", seguidos pelos delitos ecológicos, crimes contra a saúde pública, publicidade enganosa, corrupção, entre outros. Assim, para coibir essa marginalidade "socialmente construída" pela mídia, os autores supramencionados, embasados no pensamento de Baratta (1993 apud SODRÉ; SOARES; KOSOVSKI, 1994), asseguram que fazse necessário o exercício da reflexão crítica de cada cidadão, saindo do seu posto de mero espectador para se engajar nos "processos democráticos de produção de informações sobre a criminalidade".

Por final, podemos tratar a questão da violência do ponto de vista cultural. Desde as brincadeiras de criança e as canções de ninar, estamos fomentando valores voltados à cooperação, à construção de amizade e da paz ou à competição, à dominação e ao poder? Grande parte das nossas brincadeiras tem uma abordagem competitiva. Estudiosos têm se preocupado em estudar o impacto das brincadeiras e dos jogos no comportamento das crianças. Bay-Hinitz, Peterson e Quilitch (1994) demonstraram que, quando crianças brincam com jogos cooperativos, suas agressões diminuem e os comportamentos cooperativos aumentam; inversamente, quando brincam com jogos de competição, há um aumento de comportamentos agressivos e comportamentos cooperativos diminuem. Somam-se a isto os brinquedos de guerra, utilizados nos países que não estão em situação de guerra, que contribuem para criar a impressão que a guerra é uma atividade aceitável. (HINDE, 1988)

Este capítulo está estruturado em seis partes. Sucedem a esta introdução, em que foram explanados os objetivos e a justificativa, o referencial teórico, quando se apresenta o conceito de paz, conceito central neste estudo, a apresentação das duas perspectivas teóricas - a Psicologia da Paz e o relacionamento interpessoal - e discute-se 
o diálogo possível entre esses dois campos de saberes. A abordagem metodológica adotada e os resultados são explicitados na sequência, abordando de forma mais detalhada a organização alvo do nosso estudo, as notas biográficas dos participantes e os diversos aspectos sobre relacionamentos e paz. Ainda nesta parte, apresenta-se a discussão dos dados coletados intercalando com o referencial teórico e o olhar dos pesquisadores. Por último, encontram-se as considerações finais e as referências que serviram de suporte teórico para o desenvolvimento deste estudo empírico.

\section{Referencial teórico}

No sentido de trabalhar a questão da paz, começamos pela operacionalização desse termo central utilizado na nossa pesquisa. Doravante, apresentaremos as duas perspectivas teóricas: a Psicologia da Paz e o relacionamento interpessoal.

\section{Conceito de Paz}

A palavra paz vem do latim pace e apresenta sete acepções de acordo com o Dicionário Aurélio. (FERREIRA, 2010) São elas:

1) ausências de lutas, violências ou perturbações sociais, tranquilidade pública, concórdia, harmonia;

2) ausência de conflitos entre pessoas, bom entendimento, harmonia;

3) ausência de conflitos íntimos, tranquilidade de alma, sossego;

4) situação de um país que não está em guerra com outro;

5) restabelecimento de relações amigáveis entre países beligerantes, cessão de hostilidades;

6) tratado de paz; e

7) ausência de agitação ou ruído, repouso, silêncio, sossego. 
De acordo com o Dicionário de Ciências Sociais (SILVA, 1988), a paz é, antes de tudo, um termo próprio das relações internacionais, e pode referir-se ao fim de determinadas hostilidades: como a paz de Vestfália, a paz de Versalhes. Em um sentido mais amplo, pode indicar:

1) a inexistência de hostilidades;

2) a amizade verdadeira; ou

3) certas instituições que têm sido bem sucedidas nas suas gestões para o bom relacionamento de dois ou mais Estados ou dos Estados em geral.

Immanuel Kant é considerado o primeiro pensador a dar um tratamento jurídico-político ao conceito de paz, que deixou de ser tratada de forma religiosa e assume uma ideia ligada à construção social. (OLIVEIRA, 2007) Pode-se afirmar que, até o final da Segunda Guerra Mundial, a paz era considerada pelo seu aspecto negativo, como sendo a ausência de guerra. A partir daí, Galtung (1969), um dos teóricos da nova área de estudos chamada de peace research, apresenta um novo conceito de paz, que contempla dois aspectos: $\mathrm{o}$ de paz negativa, que é a ausência de violência direta, e paz positiva, que é a ausência de violência estrutural. Para Christie e colaboradores (2008), violência estrutural é resultado da forma como as instituições estão organizadas, que privilegiam algumas pessoas com bens materiais e influência política que afetam o seu bem estar em detrimento do bem estar de outras pessoas. Assim, a paz positiva refere-se à promoção de arranjos sociais que reduzam a injustiça social e econômica, as desigualdades de raça, de gênero e os desequilíbrios ecológicos como barreiras à paz.

Finalmente, a paz é considerada dentro de uma perspectiva de construção social expressa nas diretrizes da Organização das Nações Unidas (ONU) criada em 1945. Isso ainda fortalecido com a fundação da agência da ONU especializada em educação: a Organização das Nações Unidas para Educação, Ciência e Cultura (Unesco). Se a 
paz era algo em construção, seria importante trabalhar a formação de uma cultura de paz: "que as guerras nascem nas mentes dos homens, é na mente dos homens que devem ser erguidas as defesas da paz" como consta na declaração da sua constituição.

\section{Psicologias da paz: um breve histórico}

Preocupações com guerra e paz estão na obra de psicólogos desde o início do século XX. Segundo alguns autores, o primeiro psicólogo da paz teria sido William James (DEUTSCH, 1995), que afirmou que a guerra proporciona aos seres humanos oportunidades para expressar suas inclinações espirituais para o autossacrifício e honra pessoal. Para acabar com a guerra, deveriam ser achados os "equivalentes morais” para expressar esses valores humanos. (JAMES, 1995)

Segundo Christie e colaboradores (2008), no final da Segunda Guerra Mundial, 13 psicólogos norte-americanos, incluindo Gordon Allport, Edna Heidbreder, Ernest Hilgard, Otto Klineberg, RensisLikert e Edward Tolman, escreveram um manifesto dos psicólogos intitulado A natureza humana e a paz, assinado por cerca de 4 mil psicólogos. (SMITH, 1999) O manifesto argumentava que a guerra poderia ser evitada por ter sido construída pelo homem. Allport (1954) concluiu que o conflito cresce com a ignorância do adversário e que o contato entre grupos em conflito é crucial para reduzir a inimizade e o preconceito. Nesse sentido, Pettigrew (1998) também trabalhou com a teoria dos contatos intergrupos e citou quatro condições chaves para que o resultado seja positivo:

1) que os grupos apresentem o mesmo status dentro da referida situação;

2) que as metas sejam conjuntas;

3) que, para o alcance dessas metas, seja necessária a cooperação intergrupal; e

4) que tenha o suporte de autoridades, leis e/ou regulamentos. 
A Guerra Fria criou o medo da guerra nuclear e fomentou o desenvolvimento da Psicologia da Paz. Em 1961, uma coleção de artigos sobre "Psicologia e política na era nuclear" foi publicado no Journal of Social Issues (RUSSELL, 1961), por autores como Urie Bronfenbrenner, Charles Osgoode e Morton Deutsch, considerada por Christie e colaboradores (2008) um importante avanço teórico da área.

A Guerra do Vietnã gerou livros como Misperception and the Vietnam war (WHITE, 1966), International behavior: a social-psychological analysis (KELMAN, 1965) e The psychological dimension of foreign policy. (RIVERA, 1968) Segundo Christie e colaboradores (2008), estas publicações contrastavam com as anteriores sobre guerra e paz. O nível de análise mudou de um foco exclusivo no comportamento de indivíduos para um foco no comportamento das nações e os psicólogos começaram a enfatizar a prevenção da guerra, apresentando uma posição crítica em relação à política externa dos Estados Unidos. (MORAWSKI; GOLDSTEIN, 1985)

Outra onda de interesse pela paz surgiu nos anos 1980, devido às hostilidades entre líderes das superpotências e a consciência de que a ameaça da guerra nuclear era baseada no comportamento humano, de modo que a psicologia tinha um papel central a desempenhar na redução da ameaça. (WAGNER, 1985; WALSH, 1984) Nessa época, White (1986b) editou o livro Psychology and the prevention of nuclear war, que influenciou o início da Psicologia da Paz, conceituando a ameaça da guerra nuclear em termos psicopolíticos. White (1986a) tratou das dimensões psicológicas da corrida nuclear com ênfase nas percepções mutuamente distorcidas e padrões de comunicação destrutivos na competição por aliados. Vários tópicos ligados à paz entre Estados Unidos e União Soviética apareceram no Journal of social issues. O número especial "Beyond de terrence" forneceu bases conceituais para melhorar as relações entre superpotências. (LEVINGER, 1987)

No ano seguinte, outra edição do Journal of social issues teve como foco a "Psicologia e a promoção da paz". (WAGNER; RIVERA; 
WATKINS, 1988) A paz foi definida não apenas como ausência da guerra, mas, em termos ativos, como a construção de relações cooperativas entre povos e nações em longo prazo. No final dos anos 1980, o problema da imagem do inimigo (BRONFENBRENNER, 1961) foi reavaliada com maior ênfase nos vieses perceptuais e cognitivos. (HOLT; SILVERSTEIN, 1989)

A ameaça nuclear dos anos 1980 deu início a uma preocupação entre alguns psicólogos que passaram a se identificar como psicólogos da paz (peace psychologists) e, em 1991, criaram a Divisão 48 da American Psychological Association (APA). (WESSELLS, 1996) Contudo, no fim do século XX, a preocupação norte-americana com a guerra nuclear recrudesceu e a Psicologia da Paz começou a lidar com novas ameaças à paz e ao bem estar humanos, incluindo insurgências armadas internacionais, deterioração ambiental, populações deslocadas, entre outros. Segundo Christie e colaboradores (2008), vários temas estão emergindo na área, e apresentam uma:

1) maior sensibilidade ao contexto geo-histórico;

2) perspectiva mais diferenciada sobre os significados e tipos de violência e paz; e

3) visão sistêmica ou multinível dos determinantes da violência e da paz. (CHRISTIE, 2006a, 2006b)

As preocupações da Psicologia da Paz pós-Guerra Fria se tornaram mais diversas, globais e formatadas por contextos geo-históricos locais. No Ocidente, a pesquisa recente tem sido dominada por esforços para compreender e evitar o terrorismo. (MOGHADDAM, 2005; MOGHADDAM; MARSELLA, 2005; WAGNER, 2006) No Oriente Médio, os estudos tem focalizado os conflitos religiosos e éticos, principalmente em Israel e seus vizinhos, Irlanda do Norte e África do Sul. (HARE, 2006) Na Oceania, as pesquisas têm procurado entender as dimensões psicológicas da reconciliação com os aborígenes na Austrália. 
Milhares de pesquisas sobre Psicologia da Paz desde a Guerra Fria foram revisadas em Peace psychology: a comprehensive introduction. (BLUMBERG; HARE; COSTIN, 2007) Contudo, o texto mais utilizado no campo interdisciplinar dos estudos da paz é o de Barash e Webel (2002), cuja obra tem uma quantidade substancial de conteúdo psicológico. Nos dois últimos anos, foram lançadas duas enciclopédias sobre a temática. The Oxford international encyclopedia of peace, lançada em 2010, tendo como editor chefe Nigel Young. Essa enciclopédia focaliza o campo interdisciplinar dos estudos sobre a paz e apresenta uma pesquisa dos fatos políticos, históricos, teóricos e filosóficos ligados à paz e ao conflito desde a antiguidade aos dias atuais. A outra enciclopédia, The encyclopedia of peace psychology, foi lançada em 2011, sob a responsabilidade de edição de Daniel Christie e disponibilizada também eletronicamente, através da Wiley Online Library. Essa obra examina as dimensões psicológicas dos estudos sobre paz e conflito, e conta com a contribuição de vários pesquisadores e ativistas da área.

A Divisão de Psicologia da Paz (Divisão 48) da American Psychological Association, foi criada em 1991. Segundo a divisão, os objetivos da Psicologia da Paz são "aumentar e aplicar o conhecimento psicológico na busca da paz [...] [incluindo] ambos a ausência de conflito destrutivo e a criação de condições sociais positivas que minimizem a destruição e promovam o bem estar humano.” (SOCIETY FOR THE STUDY OF PEACE, CONFLICT, AND VIOLENCE, [2006]) Segundo Christie e colaboradores (2008), a Psicologia da Paz pode ser aplicada para promover a paz nas famílias, locais de trabalho, comunidades e entre nações.

\section{Psicologias da Paz: em busca de um arcabouço conceitual}

Ardila (2001) pontua que a Psicologia da Paz tem por missão desenvolver sociedades sustentáveis por meio da prevenção do conflito destrutivo, da violência e da mitigação de suas consequências, o empoderamento das pessoas e a construção da cultura da paz e 
de uma comunidade global. O autor define esse campo de estudo como,

O campo de investigação e aplicação que utiliza os achados científicos, os métodos e as teorias da psicologia, para a compreensão e modificação dos problemas associados à paz, guerra, violência, agressão e os conflitos entre grupos, comunidades, instituições e nações. (ARDILA, 2001, p. 40)

Souza e colaboradores (2006) definem Psicologia da Paz como "campo de estudos e práticas em Psicologia que aborda as temáticas da paz, da guerra, do conflito e da violência”. Acrescenta que,

[...] o objetivo fundamental é promover uma convivência mais pacífica entre indivíduos, grupos humanos ou nações. Possibilita a criação de novas estratégias de resolução de conflitos, bem como a consolidação ou desenvolvimento das já existentes.

Vollhardt e Bilali (2008, p. 13) trabalham os conceitos de Psicologia da Paz e Psicologia Social e definem o estudo social e psicológico da paz como,

O campo da teoria e prática psicológica visando a prevenção e mitigação da violência estrutural e direta entre membros de diferentes grupos sociopolíticos, assim como a promoção de cooperações e uma orientação prossocial que reduzam a ocorrência de violência intergrupal e violência na sociedade e fomente relações intergrupais positivas.

A Psicologia da Paz apresenta um amplo campo de estudo com característica multidisciplinar. Ardila (2001) e Souza (2003) enumeram alguns desses temas: origem da agressão e a influência dos fatores biológicos e dos fatores culturais, a guerra e seu lugar na história da humanidade, a solução de conflitos, o terrorismo, a origem ontogenética dos conceitos de guerra e paz, a violência política, social e econômica contra os grupos minoritários (crianças, mulheres, idosos, imigrantes, asilados), a violência sexual, a comunicação entre os grupos em conflitos, formação de valores em crianças e adultos 
- como cooperação, solidariedade e respeito aos direitos humanos. A Psicologia da Paz trabalha na linha da formação de uma cultura de não violência, educação para a paz e configura-se como uma nova abordagem nas relações internacionais e na prevenção de formas futuras de conflito e violência.

De acordo com Christie e colaboradores (2008), a Psicologia da Paz pós-Guerra Fria deve muito ao trabalho conceitual de Johan Galtung (1969), que diferenciou violência direta e estrutural. Violência direta é episódica, tipicamente ferindo ou matando pessoas rápida e dramaticamente. Em contraste, a violência estrutural representa uma ameaça crônica ao bem estar humano, ferindo ou matando pessoas lentamente por meio de arranjos sociais relativamente permanentes. Episódios de violência aberta são frequentemente intencionais, pessoais, instrumentais, e por vezes politicamente motivados. A violência estrutural é o resultado do modo como instituições estão organizadas, privilegiando algumas pessoas com bens materiais e influência política em assuntos que afetam seu bem estar enquanto retira de outros. Essas estruturas são arranjos sociais relativamente imunes à mudança. Essa distinção é amplamente usada nos estudos da paz. (BARASH; WEBEL, 2002; BROCK-UTNE, 1985)

Relacionada à violência estrutural, está a violência cultural (GALTUNG, 1996), referindo-se à esfera simbólica de nossa existência que reforça episódios ou estruturas de violência. Por exemplo, a “doutrina da guerra justa” é uma narrativa cultural que apoia episódios de violência, especificando as condições sob as quais a violência direta é justificada.

Galtung (1975) também diferenciou três tipos de atividades pela paz: manter a paz (peace keeping), promover a paz (peace making) e construir a paz (peace building) como diferentes ainda que complementares. Manter a paz é uma resposta a uma situação aguda e tipicamente envolve a contenção da violência e a separação forçada de combatentes em potencial. Promover a paz busca chegar a acordos dentro de uma situação de conflito. Construir a paz é uma tentativa mais 
proativa em uma sociedade pós-conflito, buscando reduzir a violência estrutural em um esforço para evitar o conflito e a violência no futuro.

Os aspectos teóricos da Psicologia da Paz estão se tornando cada vez mais diferenciados e sensíveis ao contexto geo-histórico. Eventos violentos são vistos como manifestações de interações entre forças destrutivas imersas em fatores sociais, culturais e históricos. É importante ressaltar que os psicólogos da paz estão engajados em pesquisa e prática multinível, investigando os elos recíprocos entre o nível psicológico de análise e fenômenos macro, principalmente no nível político e cultural. (CAIRNS; DARBY, 1998; CHRISTIE, 2006a, 2006b; KELMAN, 1995; PILISUK, 1998; SCHWEBEL, 1997; SMITH, 1998; WAGNER, 2002; WESSELLS, 1999)

Um dos arcabouços conceituais que serve de base para a presente investigação foi proposto por Christie e colaboradores (2008). Esse arcabouço, para a Psicologia da Paz, tem como foco não somente a paz negativa, ou seja esforços para reduzir episódios violentos, mas também a paz positiva (GALTUNG, 1985; WAGNER, 1988), que se refere à promoção dos arranjos sociais que reduzam injustiças sociais, raciais, de gênero, econômicas e ecológicas como barreiras para a paz. Assim, uma paz compreensiva não eliminaria apenas formas abertas de violências (paz negativa), mas também criaria uma ordem social mais igualitária atendendo as necessidades básicas e os direitos de todas as pessoas (paz positiva). A busca de ambas articula-se com a definição de paz da Unesco, que afirma que não pode haver paz genuína quando os direitos humanos mais elementares são violados ou enquanto situações de injustiça continuarem a existir. Assim, a paz é incompatível com a fome, a extrema pobreza e a recusa dos direitos dos povos à autodeterminação. "A única paz duradoura é uma paz justa baseada no respeito por direitos humanos." (UNESCO, 1983, p. 261)

Segundo Christie e colaboradores (2008), a paz negativa inclui três tipos de relacionamentos: o conflitivo (quando a percepção de alvos incompatíveis domina o relacionamento), o violento (destru- 
tivo, dominado por episódios de violência) e o pós-violento (dominado por não violência, mas com potencial para retorno ao conflito ou violência). Pontos de entrada para a promoção da paz negativa incluem a administração de conflito não violento, a cessação da violência e a construção da paz pós-violência.

O potencial para um episódio violento existe quando o estado predominante de um relacionamento é conflituoso. Os psicólogos da paz veem o conflito como universal, surgindo no contexto de incompatibilidades reais ou percebidas entre grupos e indivíduos. Contudo, o conflito não leva necessariamente a ação violenta e pode mesmo dar oportunidade para a construção de relações construtivas. Os autores destacam três teorias que explicam as condições sob as quais o conflito pode surgir: a teoria do conflito de grupo realista, a teoria da privação relativa e a teoria da privação absoluta. A primeira afirma que a hostilidade é provável de ocorrer quando grupos competem por recursos escassos. (CAMPBELL, 1965; SHERIF, M.; SHERIF, C., 1953)

Mas mesmo sem recursos limitados, o conflito pode surgir por privação relativa percebida. Estudos sobre a teoria da privação relativa têm demonstrado que a percepção por um grupo de uma discrepância entre seu padrão de vida e o de outro grupo pode resultar em conflito e hostilidade intergrupo. Daí, em nível macro, a tendência de globalização do capitalismo pode aumentar o preconceito intergrupo devido à percepção que um grupo de referência está perdendo base econômica ou política em relação a outro grupo.

Em terceiro lugar, sem considerar diferenças percebidas, a privação absoluta pode disparar o conflito. Condições de vida difíceis, como privação econômica severa, podem frustrar a satisfação de necessidades e conduzir à adoção de ideologias destrutivas nas quais os outros são vistos como barreiras para a satisfação de necessidades. Privação absoluta pode ser uma precondição para genocídio.

Do ponto de vista prático, a questão de como administrar conflito não violentamente ocupa posição central para os psicólogos da paz. A expressão administração de conflito refere-se aos esforços 
para evitar episódios violentos devido a diferentes visões (administração do conflito) ou por chegar a acordo (resolução de conflito).

Embora psicólogos da paz distingam conflito e violência, o conflito pode ser uma condição antecedente para episódios violentos. Uma vez que um relacionamento torne-se dominado por episódios violentos, a cessão da violência é crucial. A pacificação bem sucedida que separa combatentes em potencial e reduz a probabilidade de episódios violentos pode lançar a base para ações de peacemaking em que as partes começam a trabalhar visando resultados mutuamente satisfatórios.

Embora as ações para manter a paz (peace keeping), com o objetivo de separar combatentes, sejam frequentemente a primeira ação em casos de violência, em 1992, o secretário geral da ONU, Boutros Boutros-Ghali, propôs que as intervenções pela paz devessem ir além da ênfase tradicional na pacificação militar e se voltassem para as causas, para a raiz do conflito. Nesse sentido, segundo Christie e colaboradores (2008), tem-se reconhecido que o fundamento para uma paz duradoura requer:

1) “missões integradas" nas quais processos de pacificação e construção da paz estejam intimamente ligados;

2) desarmamento, desmobilização e reintegração de combatentes; e

3) novas estruturas políticas mais transparentes e igualitárias. (EIDE et al., 2005)

Psicólogos da paz têm se tornado mais ativos na pacificação e na construção da paz em situações pós-violência, particularmente quanto à avaliação e tratamento de traumas, apoio à resiliência e desenvolvimento comunitário e facilitação de diálogo e reconciliação.

A interdependência de indivíduos saudáveis e desenvolvimento da comunidade é amplamente reconhecida por psicólogos comunitários e clínicos. (LUMSDEN, 1997) Em termos mundiais, desde os anos 1990, a maioria das instâncias de violência tem sido interna, em 
comunidades (ERIKSSON; WALLENSTEEN; SOLLENBERG, 2003) e entre civis. (SIVARD, 1996) Violência baseada na comunidade é intensamente pessoal, envolvendo vizinhos, amigos e familiares.

Psicólogos da paz reconhecem que restaurar o funcionamento psicológico é crucial, inclusive para interromper os ciclos de violência frequentemente perpetuados pela transmissão de trauma entre gerações. (LUMSDEN, 1997) Inserir processos de reconciliação na estrutura das comunidades é crucial para a promoção da paz. Um ponto chave para psicólogos da paz em contextos de pós-violência é como auxiliar as pessoas a lidar com a experiência violenta enquanto promove a reconciliação mais amplamente na sociedade. O trabalho de reconciliação está evoluindo de um foco exclusivo no estresse póstraumático para uma maior variedade de problemas de saúde mental, incluindo luto e depressão e temas psicossociais chaves, como separação familiar, desconfiança interpessoal e intergrupal e a destruição de recursos da comunidade.

Relacionamentos ocorrem dentro de um contexto estrutural e cultural. Enquanto os processos de paz negativa têm três pontos de entrada dependendo da fase do relacionamento, oportunidades para processo de paz positiva são universais e podem tomar lugar em qualquer ponto do relacionamento sempre que injustiças sociais estiverem presentes. Quando o relacionamento é caracterizado por conflito, várias estratégias de administração de conflito são apropriadas para promover a paz negativa. Ao mesmo tempo, a paz positiva, transformando a estrutura das relações em um arranjo mais igualitário (LEDERACH, 2003), também pode ter lugar.

O modelo proposto por Christie e colaboradores (2008) incorpora as abordagens positiva e negativa da paz, integrando intervenções reativas (paz negativa) e intervenções proativas (paz positiva) em unidades de análise interpessoal, intergrupal e internacional. Tal abordagem reconhece que episódios violentos têm raízes estruturais e culturais. Em violência doméstica, por exemplo, a causa proximal pode ser um conflito interpessoal que avança para violência. No nível 
estrutural, a violência doméstica está enraizada na assimetria de poder e na dependência econômica da mulher.

Christie e colaboradores (2008) denominam sua abordagem como uma perspectiva multinível (a Psicologia da Paz). A paz duradoura requer não apenas a remoção das causas proximais da violência, mas também voltar-se para as raízes estruturais e culturais do problema. Independentemente do tamanho da unidade de análise (interpessoal, intergrupal ou internacional), ou ambiente (família, comunidade, entre outros), a paz sustentável requer intervenções multiníveis que integrem processos de paz negativa e positiva.

A análise multinível de Berntson e Cacioppo (2004) deixou claro que um evento alvo em um nível de análise pode ter múltiplos determinantes dentro e entre níveis de análise. Assim, há a necessidade de resistir ao reducionismo na análise multinível ao relacionar processos psicológicos no nível micro com eventos nos níveis cultural e político de análise.

Segundo Blumberg (2007), houve um aumento significativo no número de referência ao tema, a partir dos anos 1970, de acordo com registros no PsycINFO. De acordo com Christie e colaboradores (2008), há uma convergência entre a Psicologia Positiva e a Psicologia da Paz para a criação de condições sociais positivas, mas os autores não identificaram nenhum livro texto de psicologia com um capítulo sobre Psicologia da Paz.

Poucos estudos sobre Psicologia da Paz têm sido desenvolvidos no Brasil. Um deles foi a pesquisa de caráter exploratório com estudantes de Psicologia sobre a relação entre psicologia e paz. (SOUZA et al., 2006) Os estudantes demonstraram desconhecer exemplos do envolvimento da psicologia com a paz, mas afirmaram que a psicologia pode contribuir para a paz já que trabalha para o bem estar do indivíduo ou como ciência que estuda o ser humano e as relações deste consigo mesmo (paz interior) e com as pessoas (paz social e paz mundial). 


\section{A pesquisa sobre relacionamento interpessoal: um breve histórico}

O tema relacionamento interpessoal tem sido abordado por diversos teóricos em várias disciplinas, não apenas na Psicologia, mas também nas áreas biológicas e sociais, além de receber contribuições da Sociologia e Antropologia. (VENTORINI; GARCIA, 2004) Voltando no tempo, pode-se afirmar que a questão das relações humanas foi alvo de reflexões desde a Antiguidade por pensadores gregos (Aristóteles e Platão) e romanos (Cícero). É muito conhecida a famosa frase de Aristóteles: "a amizade pode existir entre as pessoas mais desiguais. Ela as torna iguais”. Contudo, a investigação científica sobre o tema se desenvolveu nos últimos 40 anos e teve como pioneiros; Michel Argyle, Henry Sullivan, John Bowlby e Fritz Heider. Duck e Hinde contribuíram para estabelecer os estudos sobre relacionamento interpessoal como área autônoma de pesquisa, que se solidificou com a criação de sociedades científicas internacionais e a realização de congressos que deram visibilidade a área e a seus estudos.

Segundo Garcia (2005), na década de 1980, Steve Duck atuou de forma decisiva para a organização da International Society for the Study of Personal Relationships (ISSPR) e da revista Journal of social and personal relationships. Em 1987, foi realizada a Conferência Internacional sobre Relacionamento Interpessoal, em Iowa, nos Estados Unidos, e foi criada a International Network on Personal Relationships (INPR). Em junho de 2002, deu-se a fusão dessas duas organizações e fundada a International Association for Relationships Research (IARR). Atualmente conta com cerca de 700 pesquisadores em 20 países.

No Brasil, já foram realizados três congressos brasileiros sobre pesquisa do relacionamento interpessoal, em 2009, 2011 e 2013, e um encontro latino-americano sobre o tema, em 2013. As pesquisas sobre relacionamento interpessoal tem se focalizado nos relacionamentos entre pais e filhos, amigos e parceiros românticos. Percebe-se, en- 
tretanto, uma grande demanda e relevância desses estudos no âmbito organizacional, considerando a sua importância para a gestão do clima organizacional e para qualidade de vida no trabalho.

\section{A pesquisa sobre relacionamento interpessoal: em busca de um arcabouço conceitual}

A área de investigação sobre relacionamento interpessoal é marcada pela diversidade teórica e metodológica. Dessa forma, cabe a cada investigador definir como abordar seu tema de pesquisa, o presente estudo toma como referencial teórico a obra de Robert Hinde sobre relacionamento interpessoal.

Robert Hinde influenciado por teóricos ligados à Etologia Clássica como Konrad Lorenz, Karl Von Frisch e Nikolas Tinbergen (os três laureado com o Prêmio Nobel de Fisiologia ou Medicina, em 1973), propõe uma orientação teórica baseada nos princípios da Etologia. (GARCIA, 2005) Hinde buscou sistematizar a produção na área e organizou 1.600 textos sobre o tema, principalmente nas décadas de 1970, 1980 e 1990 e escreveu três livros sobre o tema: Towards under standing relationships (1979), Individuals relationships and culture (1987) e Relationships, a dialetical perspective (1997) e buscava a integração dos estudos sobre relacionamento interpessoal que vinham sendo desenvolvidos pelas diversas disciplinas da área social, médica e das ciências naturais.

Garcia (2005) apresentou a contribuição da Etologia Clássica, principalmente através Konrad Lorenz, John Bowlby e Robert Hinde para os estudos sobre relacionamento interpessoal. Essa contribuição também foi discutida por Garcia e Ventorini (2005), que apontaram a ênfase na descrição como um meio para compreender a dinâmica dos relacionamentos. Além da base descritiva, esses autores citam a ênfase dada por Hinde à classificação, análise e síntese dos resultados da análise, o mover-se entre níveis de complexidade e a ênfase na questão da função, evolução, desenvolvimento e causação. 
Garcia (2005) discutiu ainda a influência da teoria de sistemas na proposta de ciência apresentada por Hinde e a contribuição dos estudos desse autor para a Psicologia Organizacional e para a Administração. Afirmou que “[...] um dos desafios para a ciência da administração é lidar adequadamente com pessoas e seus relacionamentos nas organizações.” (VENTORINI; GARCIA, 2004, p. 119)

Hinde foi o organizador da área do relacionamento interpessoal, tanto do ponto de vista teórico quanto do ponto de vista de estabelecer orientação para os estudos empíricos. Segundo Garcia e Ventorini (2005), para organizar a área de pesquisa sobre relacionamento interpessoal, Hinde parte do conteúdo das interações, passando para a sua diversidade e qualidade. Discute ainda a reciprocidade e complementaridade, a intimidade, a percepção interpessoal e o compromisso, pois essas categorias ajudariam a organizar dados descritivos sobre relacionamentos.

O modelo teórico de relacionamento interpessoal proposto por Hinde (1997) é formado por um sistema de relações dialéticas nos diferentes níveis de complexidade que afetam e são afetados uns pelos outros, e dentre eles, partindo de processos psicológicos, passando pelo comportamento individual, pelas interações, relacionamentos, grupos e sociedade e ainda a estrutura sociocultural e pelo ambiente físico. Cada um desses níveis deve ser visto como envolvendo processos em contínua mudança, que se interrelacionam e se influenciam mutuamente e não como entidades estanques. Hinde (1997) ressalta que se deve considerar as diferenças entre esses níveis.

Os dois primeiros níveis referem-se à instância individual. O primeiro é formado pelos processos psicológicos (internos ao indivíduo). Esses processos são formados pelas atitudes, expectativas, intenções, emoções, crenças, autoestima, percepção etc. O segundo nível pelo comportamento individual. O terceiro é composto pelas interações, que Hinde (1997) define como envolvendo no mínimo duas pessoas por um curto espaço de tempo e que durante o processo de interação, o comportamento de cada indivíduo é influenciado pelos seus objetivos e 
interesses, por suas normas, valores, percepção e, também, pelo contexto. Nessa instância, cada participante procura entender os objetivos e estratégias do outro e ter uma melhor compreensão dos seus próprios objetivos e estratégias. No quarto nível, os relacionamentos envolvem uma série de interações entre os indivíduos, cada interação é influenciada pelas interações passadas e pelas expectativas sobre interações futuras. Assim, os relacionamentos não envolvem apenas os comportamentos, mas desejos, emoções, julgamentos etc., e têm continuidade mesmo com ausência de interações.

Um quinto nível é formado pelo grupo. Hinde (1997) define como grupo aquela instância que os membros se identificam como participantes e que as interações são mediadas pelas regras e normas e outras características desse grupo. Cada relacionamento engloba um conjunto de outros relacionamentos, que constitui o grupo psicológico para o autor.

Todos esses níveis estão inseridos na sociedade e são influenciados e influenciam a estrutura sociocultural (normas, valores, crenças) e pelo ambiente físico.

Esse modelo proposto por Hinde (1997) para a compreensão dos relacionamentos é constituído por quatro estágios. O primeiro referese à descrição dos fenômenos, o segundo é formado pela discussão de processos subjacentes, o terceiro estágio refere-se ao reconhecimento das limitações, e o último à ressíntese. (GARCIA; VENTORINI, 2005) A proposta de Hinde (1997) para a descrição dos relacionamentos envolve, em essência, a descrição das interações - conteúdo e qualidade, descrição das propriedades advindas da frequência relativa e padronização da interação dentro do relacionamento e a descrição de propriedades mais ou menos comuns a todas as interações dentro do relacionamento. O autor inclui também a comunicação verbal e não verbal como elementos importantes para a compreensão do relacionamento.

Como citado, para que haja relacionamento, Hinde (1997) salienta que as interações entre indivíduos que se conhecem devem se repetir e, para proceder-se a descrição de um relacionamento, são 
necessárias informações sobre as atividades de cada um, que devem incluir dados referentes ao que os participantes fazem, pensam e sentem nos diversos níveis de complexidade, desde as interações, aos relacionamentos e grupos. O autor afirma que há relacionamento se os indivíduos têm uma história comum de interações passadas e o curso da interação atual é influenciado por elas. As atitudes, expectativas, intenções e emoções dos participantes são fatores intervenientes na construção dos relacionamentos. Assim, essas características psicológicas das partes como demais características pessoais - o posicionamento quanto a normas culturais, sociais e organizacionais, autoconceito, autoestima, valores religiosos, habilidades de comunicação, energia dispensada nos relacionamentos, entre outras - exercem forte influência sobre o rumo dos relacionamentos.

Os relacionamentos, segundo Hinde (1997), podem ser agrupados no sentido de formar uma rede de relacionamentos, como a família, o grupo de vizinhança, da igreja, entre outros, e a partir daí compor o grupo social. Contudo, essas redes de relacionamentos podem sobrepor-se ou manter-se completamente separadas, comportando-se como grupos distintos, uns em face dos outros. Assim como nas interações e relacionamentos, cada grupo tanto influencia o ambiente físico e biológico em que está inserido como é influenciado por ele. O autor reconhece a existência de níveis distintos de complexidade no comportamento social. Cada um deles (interações, relacionamentos, grupos sociais) possui propriedades próprias. (HINDE, 1997)

A natureza de uma interação ou de um relacionamento depende de ambos os participantes, do comportamento que os indivíduos manifestam em cada interação, da natureza do relacionamento, a qual é influenciada pelo tipo de grupo a que está relacionada. Desse modo, cada um desses níveis não somente influencia o ambiente físico e a estrutura sociocultural (ideias, mitos, valores, crenças, costumes e instituições), como também é modificado por eles, como já mencionado anteriormente. 
Assim, a sequência real de interações entre duas pessoas no tempo ou a sequência potencial de interações entre duas pessoas que já interagiram no passado é o que forma o que Hinde (1997) denominou de relacionamentos diádicos e relacionamento interpessoal. No nível comportamental, um relacionamento envolve uma série de interações entre indivíduos que se conhecem. Portanto, a descrição de um relacionamento refere-se ao conteúdo do comportamento apresentado (o que fazem juntos), à qualidade do comportamento (de que forma é feito) e à padronização (frequência absoluta e relativa) das interações que o compõem. Algumas das mais importantes características dos relacionamentos dependem de fatores afetivos/cognitivos, que também devem ser considerados na descrição. Acrescenta que, além da descrição, faz-se necessário a classificação desses relacionamentos.

Em síntese, Hinde $(1997,2001)$ foi responsável por buscar integrar os diversos conhecimentos das diversas áreas sobre a temática do relacionamento interpessoal e sistematizar esses estudos. O seu modelo teórico apresenta 12 categorias de dimensões:

1) o conteúdo das interações (as atividades realizadas em conjunto);

2) a variedade das interações (quantitativo de ações diferentes que são realizadas em conjunto);

3) a reciprocidade;

4) a complementaridade (sendo essas duas últimas referindo-se às habilidades dos participantes, se são similares ou complementares);

5) a qualidade das interações e da comunicação (como fazem);

6) a frequência relativa e padronização das interações;

7) incidência e natureza dos conflitos;

8) distribuição do poder; 
9) intimidade, autorrevelação ou compartilhamento, que se refere ao grau de abertura dos aspectos emocionais e das experiências com o outro;

10) uma percepção interpessoal, que está relacionada como cada um vê o outro, se como ele é "realmente", e como cada um se vê e como se sente compreendido;

11) a satisfação em relação a qualidade do relacionamento, a percepção das necessidades supridas e, consequentemente, a busca pela continuidade, melhoria ou ruptura; e, por fim,

12) o compromisso, no sentido que os participantes comportam-se com o intuito de manter ou melhorar o relacionamento.

\section{Psicologia da Paz e relacionamento interpessoal: o diálogo possível}

Os dois referenciais utilizados (CHRISTIE et al., 2008; HINDE, 1997), devido a partirem de pontos de vista semelhantes em relação ao comportamento social humano (como a proposta de diferentes níveis de complexidade e suas relações dialéticas), são considerados compatíveis e mesmo complementares, podendo contribuir para uma visão mais ampla do tema abordado, permitindo um diálogo produtivo para as duas áreas em questão: estudos do relacionamento interpessoal e a Psicologia da Paz.

O estudo empírico, doravante apresentado, embasa-se na visão dialógica dos dois eixos desenvolvidos nos referenciais supracitados e será detalhado a seguir.

\section{Metodologia}

Foi adotada uma abordagem metodológica qualitativa. (MINAYO; DESLANDÊS; GOMES, 2010, VERGARA, 2006) Strauss e Corbin (2009, p. 23) definem esse tipo de pesquisa como “[...] qualquer tipo de pes- 
quisa que produza resultados não alcançados através de procedimentos estatísticos ou de outros meios de quantificação”. Os autores acrescentam que métodos qualitativos

[...] podem ser utilizados para obter detalhes intricados sobre fenômenos, como sentimentos, processos de pensamentos e emoções que são difíceis de extrair ou descobrir por meio de métodos de pesquisa mais convencionais". (STRAUSS; CORBIN, 2009, p. 24)

Enfim, a pesquisa qualitativa busca apreender os significados subjetivos, práticas e processos subjacentes a certos fenômenos, para um determinado grupo, em um contexto específico não se atendendo à quantidade, mas sim a significados que são compartilhados pelos membros desse um grupo. (MINAYO; DESLANDÊS; GOMES, 2010)

Os dados foram coletados através de entrevista semiestruturada que durou cerca de uma hora. O roteiro da entrevista estava organizado em partes que contemplaram o levantamento dos dados sociodemográficos e a experiência internacional do participante - experiências fora do país, sejam por turismo/viagens, estudo, trabalho e a duração dessas experiências - e as perspectivas mais gerais sobre relacionamento interpessoal, entre grupos e entre nações para a paz mundial de acordo com os participantes.

As entrevistas foram gravadas e transcritas no seu idioma de origem e posteriormente, em sua grande parte, traduzidas para a língua vernácula pela pesquisadora. As entrevistas foram realizadas em português (ambos do Brasil e de Portugal), espanhol e inglês.

Os dados foram discutidos à luz da Psicologia da Paz (especificamente quanto às contribuições de Christie) e à luz da pesquisa do relacionamento interpessoal (especificamente quanto às contribuições de Robert Hinde).

Participaram da pesquisa dez membros do Servas Internacional em dez países: Argentina, Austrália, Brasil, Canadá, Estados Unidos, França, Israel, Portugal, Malásia e Singapura. Na época da entrevista, todos ocupavam funções de liderança, seja como entrevistador, 
coordenador local, secretária nacional ou pertenciam ao Comitê Executivo Internacional (Exco). O período de atuação no Servas desses participantes variava de 7 a 26 anos. Dos dez participantes, apenas dois eram do sexo masculino e a idade variava de 33 a 83 anos. No que concerne ao estado civil, seis eram casados, uma era viúva, uma solteira e duas eram divorciadas. Os participantes pertenciam a três grupos religiosos: católicos (3), judeus (2) e budista (1), dois se classificaram como ateus e dois afirmaram não ter religião, sendo que um deles declarou-se espiritualista. Todos os participantes tinham nível de escolaridade superior e dois tinham pós-graduação.

O processo para a escolha dos participantes foi por conveniência e a realização das dez entrevistas justificada pela saturação dos dados, não se fazendo mais necessário a inclusão de novos participantes. Como afirmado por Fontanella, Ricas e Turato (2008, p. 25), “[... a amostragem por saturação é uma ferramenta conceitual de inequívoca aplicabilidade prática, podendo, a partir de sucessivas análises paralelas à coleta de dados, nortear a sua finalização”.

No que se refere aos procedimentos para coleta de dados, inicialmente foi encaminhada uma carta ao presidente do Servas, solicitando autorização para a realização da pesquisa. Alguns participantes foram contatados pessoalmente durante a realização da Assembleia Geral do Servas, realizada em Mar del Plata, Argentina, em setembro de 2009. Nesse evento, a pesquisa foi apresentada com a finalidade de demonstrar seus objetivos e procedimentos, quando foram realizadas quatro entrevistas com caráter piloto. Posteriormente, mais duas entrevistas foram realizadas por Skype e uma por telefone, para testar não apenas o instrumento como também o meio de realização (pessoalmente, por Skype e por telefone), perfazendo um total de sete entrevistas pilotos. Testado o instrumento, aqueles que aceitaram participar foram entrevistados por meio de Skype ou em um segundo contato pessoal realizado durante a celebração do $60^{\circ}$ aniversário do Servas, realizado na cidade de Goa, na Índia, em janeiro de 2010, quando outros participantes foram recrutados. Os dois outros 
participantes foram uma viajante do Servas e um contato realizado durante uma das viagens da pesquisadora. As entrevistas realizadas pessoalmente aconteceram no Brasil, Austrália, Argentina, Estados Unidos, Nova Zelândia e Índia.

Para atender os aspectos éticos, após a apresentação da pesquisa, foi garantido o anonimato e ressaltada a livre decisão em participar do estudo, inclusive podendo interromper a entrevista em qualquer momento. Em sequência, foi apresentado o Termo de Consentimento Livre e Esclarecido (TCLE) para a participação em pesquisa e solicitado a permissão para a gravação da entrevista, que, depois de transcritas, serão apagadas ao final do terceiro ano após a conclusão do estudo.

Os participantes foram identificados ao longo da pesquisa como: L1, L2, L3, L4 e, assim consecutivamente, até L10 para a preservação do anonimato. Ressalta-se que a letra L refere-se à inicial da palavra "líder".

\section{Resultados e discussão: o Servas Internacional}

O Servas Internacional (ALTIERI, 2006; KNOWLES, 1989; LUITWEILER, 1999; MULDER; VIGUURS, 2001) é uma ONG internacional, criada na Dinamarca após a Segunda Guerra Mundial, em 1949, com o objetivo de promover a paz, a compreensão e tolerância entre os povos e, assim, evitar outras guerras. O Servas está presente em mais de 125 países, oportunizando o contato entre pessoas com diferentes backgrounds, cultura e nacionalidade. Trata-se de uma rede mundial de anfitriões e viajantes, criada com o propósito de ajudar a construir a paz mundial e reforçar valores de boa vontade, entendimento e tolerância mútua por meio de contatos pessoais entre indivíduos de diversas culturas, nacionalidades e histórias de vida.

Em 1949, alguns jovens pacifistas de vários países frequentando uma escola popular de ensino fundamental em Askov, na Dinamarca, começaram um movimento chamado "Construtores da paz". Inspirados por Bob Luitweiler, um americano que se recusou a servir 
nas forças armadas e que participava de um movimento, na ocasião, conhecido como conscientious objector, eles estabeleceram um código de trabalho, estudo e viagem, abrindo seus lares para pessoas de outros países de visão similares, de modo a trabalhar ativamente pela paz. Em 1972, o Servas Internacional foi registrado na Suíça e, no ano posterior, foi incluído na lista de ONGs das Nações Unidas, tendo, até hoje, representação na ONU. No Brasil, o Servas está presente há mais de 30 anos e começou a expandir-se em 1979.

O Servas Internacional é uma federação de grupos Servas nacionais, sendo cada grupo nacional responsável por sua administração. Para um grupo nacional ter direito a tornar-se país membro com direito a voto, deve ter um mínimo de 10 membros, ter pelo menos três pessoas chaves para contato (keypeople) e ser aprovado pelo Servas Internacional. (Informação verbal) ${ }^{2}$

Para manter o status de país membro, o grupo nacional deve publicar a lista de anfitriões, no máximo, a cada dois anos, e emitir o relatório financeiro anual em pelo menos um dos dois anos anteriores à realização da assembleia geral.

O Servas é administrado, em nível mundial, pelo Exco, assessorado pelos comitês de desenvolvimento de resolução de conflitos, de auditoria, de indicação (nominations) e de descrição de cargos e estatuto e por uma coordenação do Servas jovem, um escritório de desenvolvimento de jovens, pelo editor de boletim (Servas News) e um arquivista. O Exco é composto por presidente, vice-presidente, secretário geral, tesoureiro, coordenador de listas e secretário da paz. Os ocupantes desses cargos são eleitos durante as assembleias gerais que acontecem a cada três anos. Em nível nacional, o Servas é administrado por um secretário nacional, secretário da paz, coordenador nacional de lista, editor de boletim e pelos coordenadores regionais (geralmente de cada estado). Ademais, temos a presença de entre-

2 R. Borenstein, São Paulo, out. 2009. 
vistadores que são voluntários com experiência no Servas e realizam entrevista com as pessoas interessadas em participar da organização como anfitrião ou viajante. Em alguns continentes, o Servas é administrado por um coordenador de área com mandato de três anos, escolhido até três meses após a realização de cada assembleia geral.

A palavra servas tem origem na língua esperanto e significa servir. O fundador, ainda que americano, teve o cuidado de encontrar uma palavra que tivesse significado em vários idiomas a fim de dar-lhe uma conotação mais internacional. Vale ressaltar que, inicialmente, a tendência era para o uso do nome Peace builders ou Open doors, mas a escolha da palavra servas expressava o pensamento de que "[...] as pessoas que viajassem iriam aprender com seus anfitriões como poderiam colaborar mais eficazmente em suas comunidades de origem para desenvolver programas e relações humanas livres de sementes da guerra”. (LUITWEILER, 1999, p. 28)

O Servas funciona por meio de seus membros voluntários que oferecem hospedagem (Open doors) para viajantes cadastrados que desejam conhecer o país (não apenas como turistas), e trabalham como promotores da paz, e por membros, que são viajantes que querem conhecer o país não se restringindo às áreas turísticas tradicionais. É conhecido o programa de trabalho-viagem e estudo, como exemplo do Servas Youth Language Experience (SYLE) que oportuniza aos jovens uma imersão cultural em outros países. Para esse programa foi definido a faixa etária de 18 a 35 anos.

Outro programa, denominado Servas Cultural Experience (SCE) tem sido realizado entre o Servas Brasil e Argentina. O SCE contempla pessoas não tão jovens, acima do intervalo de idade contemplado pelo SYLE.

Pode-se participar do Servas de três formas: como anfitrião (host), anfitrião por um dia (day host) e viajante (traveller). Todos devem preencher um cadastro e passar por uma entrevista com um dos líderes do Servas, que ressaltará os valores e o objetivo da organização. Depois da entrevista e do cadastro aprovado, o nome é inserido 
na lista confidencial de anfitriões (host list) daquele país com acesso apenas para os membros cadastrados. O anfitrião compromete-se, quando possível, a hospedar os viajantes independente de sexo, raça, religião, partido político e nacionalidade e o day host a receber para um passeio pela cidade ou convidar para alguma refeição em conjunto. Para ser viajante, deve-se, além do cadastro, preencher uma "carta de apresentação" com informações pessoais e interesses de viagem e passar por outra entrevista na qual serão enfatizados novamente os valores do Servas e as responsabilidades como viajante, como a elaboração de um relatório de viagem. A "carta de apresentação" então recebe um selo e assinatura do entrevistador e do viajante. Esse selo tem um pequeno custo que varia de país para país.

\section{Participantes: notas biográficas}

Nas notas biográficas dos participantes, destaca-se a experiência internacional, seja com viagem, estudos ou trabalho. Um dado importante é que os pais de oito dos dez entrevistados apresentam experiência internacional, sejam como migrantes, ou por terem trabalhado ou estudado fora do seu país de origem. Duas das entrevistadas nasceram fora do país, uma enquanto os pais estudavam e outra enquanto os pais trabalhavam, mas mantiveram a nacionalidade dos pais. Dos dez entrevistados, apenas um era de nacionalidade diferente da do país em que morava, tendo trabalhado em diversos países em vários continentes. Nove dos dez participantes já residiram fora do seu país, e vale ressaltar que o único participante que não morou além fronteiras afirmou que viajou exaustivamente e visitou mais de 50 países, como pode ser comprovado em sua residência pela presença de objetos dos países visitados. Todos fizeram viagens longas de mais de um ano, sendo que dois deles fizeram viagem de volta ao mundo. Associado a essa exposição internacional, os entrevistados apresentaram domínio de vários idiomas, sendo que três deles falam quatro idiomas de forma fluente, um entrevistado falava sete idiomas, outro, seis idiomas e somente um deles falava apenas o idioma nativo. 
É importante mencionar a forma como o participantes conheceram e o período de atuação no Servas. De acordo com as informações socializadas pelos participantes, a primeira exposição ao Servas está associada à realização de uma viagem ou ao fato de gostarem de viajar. Tiveram conhecimento do Servas ao organizar uma viagem, durante uma viagem ou por indicação de amigos, quando souberam que eles gostavam de viajar. Um entrevistado conheceu o Servas através de uma organização afim e outro, através de um folder de divulgação encontrado em um museu. Apesar de ser um movimento pela paz, os dados demonstram que as pessoas se cadastram ao Servas em virtude da possibilidade de viajar. Os participantes, como já ressaltado, são viajantes ou pessoas que já moraram fora do país. Não houve caso de pessoas que se associaram por ser um movimento pela paz.

Figura 1 - Mapa Mundi localizando os participantes e os contatos mais significativos oportunizados pelos Servas

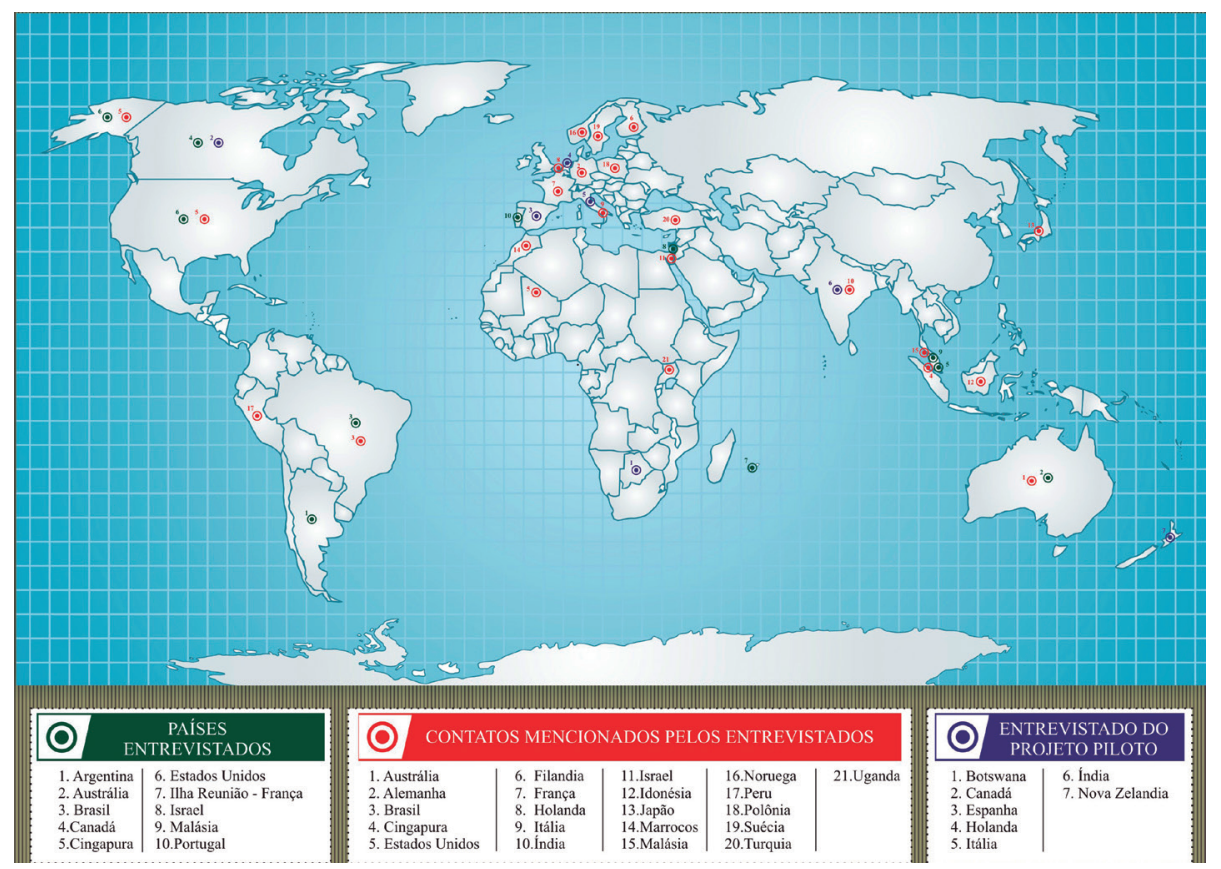

Fonte: Elaborada pelos autores. ${ }^{3}$

3 Adaptado de http://www.ibge.gov.br/paisesat/main.php. 
Durante a entrevista foram discutidos os três contatos mais significativos oportunizados pelos Servas. Um total de 28 contatos foi mencionado pelos 10 participantes. Foram 14 experiências com os anfitriões, 12 com os hóspedes e 2 com pessoas que conheceram em eventos realizados pelo Servas. A Figura 1 apresenta o país de cada participante da pesquisa e os contatos significativos mencionados por eles. A partir da vivência com esses contatos, foi discutido o papel desses relacionamentos na promoção da paz mundial.

\section{Relacionamento interpessoal e paz}

O tema relacionamento interpessoal foi tratado em vários momentos ao longo da entrevista. Assim, neste item, relata-se em mais detalhes, o papel das relações interpessoais para promover a paz internacional na perspectiva dos entrevistados. Para iniciar, de acordo com os dados obtidos, o relacionamento interpessoal é reconhecido como importante na promoção da paz internacional. Nove participantes afirmaram que a paz começa com o contato pessoal, com contato positivo entre as pessoas. Pode-se afirmar que o relacionamento interpessoal é considerado pelos participantes como o primeiro ponto e a forma provável para a promoção da paz entre os povos. A análise dos dados demonstrou ainda aspectos que influem no comportamento das pessoas e que podem influenciar a paz mundial. Pode-se relacionar esses aspectos aos processos psicológicos no modelo dos diferentes níveis de complexidade de Hinde (1997), de a pessoa ter uma mente aberta e estar disponível e ir preparada para conviver com o diferente e se superar. É necessário refletir sobre o grau de intolerância que cada pessoa apresenta, mesmo participando de um movimento para a paz, nesse caso o Servas. Ainda no que se refere aos relacionamentos interpessoais, os dados demonstraram que as pessoas que se juntam ao Servas parecem apresentar características que facilitam os relacionamentos, como mente aberta, simpatia e bom senso de humor. (HINDE, 1997) Essas características colaboram para que as pessoas sejam mais hospitaleiras, acolhedoras e procurem tratar bem umas as outras. 
A experiência do contato pessoal é fundamental para conhecer outras pessoas evitando a adoção de estereótipos que são passados adiante, especialmente em relação às pessoas de outras culturas ou raças.

Se eu, se eu viver numa comunidade onde haja alguém que diz que o bairro ao lado é habitado por pessoas que comem crianças e que se babam quando comem, assim... percebe a ideia? E eu não conhecer essas pessoas, eu vou acreditar nessas pessoas que está me dizendo essas coisas. Portanto, o melhor é eu conhecer as pessoas que vivem no bairro ao lado, e ver que, bolas, afinal não são assim tão más, não é? (L2)

Adicionalmente, o relacionamento interpessoal é considerado pelos participantes do movimento, ora sendo estudado, como o primeiro ponto e a forma provável para a promoção da paz entre os povos em conflitos. A tentativa de trabalhar a pacificação entre grupos parece ser muito difícil e a possibilidade seria iniciar a nível micro, com o relacionamento entre as pessoas desses grupos antagônicos e fazendo-as perceber os pontos, as necessidades em comum. Começariam trabalhando a partir desses pontos de convergências até atingir o grupo e, quiçá, chegando ao ponto macro. Por exemplo, através do contato entre as pessoas, trabalhando os valores de paz, seria possível superar a busca pelo poder e minimizar os interesses das fábricas de armas. Na sequência, detalha-se mais sobre o relacionamento entre grupos.

\section{Relacionamentos intergrupal e paz}

De acordo com os dados obtidos, a relação entre grupos parece ocupar uma posição secundária na visão dos participantes. As menções a relacionamento entre grupos foram escassas, como, por exemplo, a consideração de grupos etários, religiosos ou étnicos. Nesse caso, os participantes apontaram para um bom contato entre representantes desses diferentes grupos. 
Os diferentes grupos precisam proporcionar oportunidades de compartilhamento para outros que tem diferentes ideias e diferentes comportamentos e a questão do poder também foi mencionada. O participante L3 ressaltou o foco que as pessoas dão às questões materiais, financeiras e no poder em si e como isso pode impactar a paz.

Nesse mesmo sentido, L7 ressaltou que não tem muita confiança no governo, criticou os altos gastos com as reuniões do Grupo dos 20 (G20) e acrescentou que as empresas internacionais é que estão no controle neste mundo globalizado. A forma de contribuir para a paz seria através das práticas dessas empresas, caso elas apresentassem práticas mais igualitárias.

O participante L10 focalizou na questão do papel das pessoas (e seus relacionamentos), para os grupos, para as organizações, para as Nações Unidas e a possibilidade de auxiliar com políticas voltadas para a paz, e afirmou acreditar no seu protagonismo para este fim:

Eu sinto, eu tenho um importante papel referente à paz mundial. Nós todos podemos, como grupos, como pessoas, e como grupos ajudá-los para a paz mundial, que é para isso que eles se candidatam. ${ }^{4}$

O participante L9 ressaltou que a promoção da paz nestes três níveis - pessoas, grupos e nações - é uma reação em cadeia. Começa entre duas pessoas, da abertura entre elas, e ressaltou o papel do grupo. Acrescentou que no concernente aos relacionamentos intergrupos é importante a representação de todos os grupos sociais existentes em um país para a promoção da paz e o desenvolvimento da nação. (BOBBIO, 2003; CHRISTIE et al., 2008) L9 recorreu, a título de exemplo, ao caso da Colômbia e o programa de revitalização urbana da cidade "Bogotá, como vamos?". Afirmou que o programa obteve sucesso, não apenas pela parte urbanística, arquitetônica, e cultural, mas, principalmente, porque envolveu representantes das elites de Bogotá:

4 I feel I have an important role, regarding world peace. Wecanall, as groups, as individuals, and, as groups, help them toward world peace, which what they run for. 
[...] e elites aqui entendidas como quaisquer grupos sociais com as lideranças, não elites de quem tem mais dinheiro, quem pensa mais, quem tem mais projeção, elite no sentido das lideranças. Então esse movimento levou, pra mesma mesa de discussão, lideranças diversas, como líder dos empresários, como líder dos camelôs, das prostitutas, dos sorveteiros, dos estudantes e por ai em diante. (L9)

Alguns participantes pareciam não entender, quando indagados sobre como os relacionamentos entre grupos afetavam a paz mundial, contudo, quando questionados sobre os relacionamentos entre nações, afirmaram que esses relacionamentos eram permeados pelos interesses entre grupos. Convém citar que um dos fundamentos do Servas é proporcionar às pessoas dos diversos grupos oportunidades de se conhecerem e de se tornarem amigas, para assim, recusarem a fazer guerra com o país da outra. (MULDER, VIGUURS, 2001; SERVAS, 2009) Esse networking de viajantes e anfitriões facilitaria o contato de pessoas entre os diversos grupos e nações, de acordo com estudos que afirmam que o conflito cresce com a ignorância do adversário e que o contato entre grupos em conflito é crucial para reduzir inimizade e preconceito. (ALLPORT, 1954) Esta pesquisa apresenta convergência com a teoria do contato intergrupos (PETTIGREW, 1998), que afirma que a oportunidade de interação entre pessoas de diferentes grupos contribui para a diminuição de conflitos tratados de forma violenta.

O próprio movimento Servas em cada país foi visto como um grupo, por vezes. Apesar do relacionamento entre grupos fazer parte do modelo de relacionamentos de Hinde (1997), o autor não trata especificamente do tema.

O grupo constitui um dos níveis de complexidade apresentado no modelo teórico de relacionamento interpessoal apresentado por Hinde (1997). É importante mencionar que também sofre a influência e influencia a estrutura sociocultural e o ambiente físico. Conver- 
gente com este modelo, a análise dos dados confirmou a influência dos valores culturais das pessoas e de cada país nos relacionamentos intergrupais. Nesse mesmo sentido, estudiosos da Psicologia da Paz afirmaram que se pode alterar a característica competitiva dos relacionamentos, enfatizando a cooperação entre pessoas e grupos que pode ser atingida através de um processo de comunicação eficiente, compartilhamento de valores e crenças entre outros. (CHRISTIE et al., 2008) Um exemplo dessa ação foi quando os Estados Unidos alteraram seu sistema de ensino, acabando com a segregação buscando reduzir o preconceito. Galtung (1969), quando trabalhando os conceitos de paz positiva e negativa, ressaltou a noção de padrões cooperativos que buscam a colaboração entre grupos e nações - acrescentando justiça e solidariedade. Também no relacionamento entre grupos, como aconteceu no relacionamento ao nível interpessoal, apareceu como destaque às diferentes nacionalidades e a realização de atividades em conjunto.

\section{Relacionamento internacional e paz}

Nesse aspecto, a participante L9 trata do relacionamento entre nações que diz ser permeado por interesses alheios aos das pessoas que as compõem, já que são os grupos que dominam as discussões, mas o que acontece dessas discussões tem um impacto muito grande na vida de cada um. Retomou a relevância da participação das pessoas, que considerou ser necessário ter uma disponibilidade em toda a cadeia sociopolítica, dentro de um país para promoção da paz: todos precisam se sentir participantes desse processo internamente, e todos precisam gerar discussões e apoios para que país possa se projetar internacionalmente, em prol da paz.

O relacionamento entre pessoas de diversos países permite que se tenha acesso à informações mais acuradas sobre o país, além de aumentar o interesse pelos assuntos daquele país. Esse relacionamento ainda facilita a mobilidade espacial, já que fica mais fácil visitar países 
onde se tem algum contato, que, em algumas vezes, são contatos realizados nos eventos nacionais e internacionais.

O relacionamento entre nações procurando identificar se o contato com o hóspede/anfitrião de outro país alterou a visão que o participante tinha daquele país efetivou-se, geralmente, de forma positiva. Não houve histórico que o relacionamento entre pessoas de diferentes nações tivesse alterado a visão do país de forma negativa. Por conseguinte, podemos afirmar que o contato com pessoas de outros países colabora para a quebra de preconceitos e estereótipos e, assim, pode aumentar a tolerância entre as pessoas e as nações, de acordo com os princípios da Cultura da Paz (NACÕES UNIDAS, 1999), que reconhecem a necessidade de eliminar todas as formas de discriminação e manifestação de intolerância. Em suma, a análise dos dados das entrevistas nos faz compreender que os participantes consideram o relacionamento interpessoal como relevante para a paz mundial, já que, tudo começa com o contato entre duas pessoas que pode expandir para o grupo e para as nações. Por conseguinte, pode-se concluir que o relacionamento interpessoal é reconhecido como relevante na promoção da paz internacional. Ademais, foi ressaltado o papel das corporações internacionais como fundamental para a promoção da paz e a governança global, já que têm poder de ação com considerável autonomia em relação aos Estados-Nação.

Ao falar sobre as nações, os participantes focalizaram também nas características das pessoas daquele país e aspectos culturais e históricos. No que se refere às diferentes nacionalidades, foi mencionado que se a pessoa tem uma experiência positiva com alguém de um país, tem tendência a acreditar que essa experiência vai perdurar com as outras pessoas daquele país.

\section{Considerações finais}

Tanto a Psicologia da Paz quanto o estudo do relacionamento interpessoal na perspectiva de Hinde (1997) reconhecem a existência de diferentes níveis de complexidade. Pode-se dizer que o conceito de 
paz, a cultura de paz, a educação para a paz e os movimentos pela paz contemplam basicamente as pessoas como representantes de um país, destacando-se sua nacionalidade e a cultura associada a ela. No que tange ao relacionamento interpessoal, não se pode perder de vista que a nação, a sociedade, a que cada pessoa pertence afeta o relacionamento com outras pessoas.

Assim, quanto ao papel de diferentes níveis de relacionamento, pode-se propor um movimento dialético na percepção dos membros do Servas, entre pessoas e seus países, de modo que relacionar-se bem com outras pessoas de outro país é a base da paz como o movimento a constrói. O relacionamento interpessoal é a célula do internacional, sendo pouco percebido o nível intergrupal para a promoção da paz mundial, de acordo com a visão de participantes do Servas, mesmo que, em outros momentos, eles mencionem temas ligados aos grupos.

No que se refere ao papel do Servas na promoção de relacionamentos interpessoais, a amizade é destacada, pois esta também contribui para a quebra de preconceitos. Em outras respostas, os participantes reconhecem a centralidade do relacionamento interpessoal para o movimento. Também é destacada a importância que, nesses relacionamentos, as pessoas levem a sério os ensinamentos/princípios servianos para o alcance dos objetivos do Servas, de promoção da paz e tolerância entre os povos. Por outro lado, esses princípios, inclusive o de trabalho, estudo e viagem, dependem dos relacionamentos entre as pessoas para se efetivarem. Assim, para o Servas existir, faz-se necessário o contato entre as pessoas, que podem progredir para o nível de relacionamento. (HINDE,1997)

Em suma, faz-se mister destacar a relevância do contato pessoal, alterando o contato entre grupos e posteriormente entre nações. Faz-se necessário que as pessoas compreendam melhor o significado de paz, na acepção adotada neste estudo, fruto da ampliação da consciência social e, por conseguinte, e que possam influenciar os empresários, os governantes e até mesmo as políticas das Nações Unidas. Isto posto, estabelece-se a relação entre o interesse 
pessoal em viajar, a motivação para viajar, para deslocar, para a mobilidade, e o interesse em se relacionar com pessoas diversas. Contudo, a exposição ao diferente, ao outro, ou na acepção de Hinde, o contato com outros, os relacionamentos, não são suficientes para modificar preconceitos. Observa-se que o Servas consegue operar modificações e viabilizar mudanças de perspectivas em pessoas com histórico familiar de ampla exposição e percepção ao diferente.

No que se tange ao setor empresarial, destaca-se a importância das empresas e de suas ações na promoção da paz neste mundo globalizado. As ações de responsabilidade social corporativa ou, no seu sentido mais amplo, de sustentabilidade corporativa, podem colaborar, também, com os planos globais de ação, o Protocolo de Kyoto e Agenda 21 e, portanto, melhor contribuir para a promoção da paz justa que inclui o desenvolvimento sustentável.

\section{Referências}

ALTIERI, A. Ospitare la pace: leretidiospitalità e le loro potenzialitànellos cambio interculturale. 2006. 139 f. Tesi (Dottorato) - Universitàdi Pisa, Pisa, 2006.

ALLPORT, G. W. The nature of prejudice. Reading, MA: Addison-Wesley, 1954.

ARDILA, R. ¿Qué es la Psicología de La Paz? Revista Latinoamericana de Psicologia, Bogotá, v. 33, n. 1, p. 39-43, 2001.

BARASH, D. P.; WEBEL, C. Peace and conflicto studies. Thousand Oaks: Sage, 2002.

BAY-HINITZ, A. K.; PETERSON, R. F.; QUILITCH, H. R. Cooperative games: a way to modify aggressive and cooperative behaviors in young children. Journal of Applied Behavior Analysis, Lawrence, v. 27, p. 435-446, 1994.

BERNTSON, G. G.; CACIOPPO, J. T. Multilevel analyses and reductionism: why social psychologists should care about neuroscience and vice versa.

In: BERNTSON, G. G., CACIOPPO, J. T. Essays in social neuroscience. Cambridge: MIT Press, 2004.

BLUMBERG, H. H. Trends in peace psychology. In: BLUMBERG, H. H.; HARE, A. P.; COSTIN, A. (Ed.). Peace psychology: a comprehensive introduction. Cambridge: Cambridge University Press, 2007. p. 3-16. 
BLUMBERG, H. H.; HARE, A. P.; COSTIN, A. (Ed.). Peace psychology: a comprehensive introduction. Cambridge: Cambridge University Press, 2007.

BOBBIO, N. O problema da guerra e as vias da paz. São Paulo: UNESP, 2003.

BROCK-UTNE, B. Educating for peace: a feminist perspective. New York:

Pergamon Press, 1985.

BRONFENBRENNER, U. The mirror image in Soviet-American relations: a social psychologist's report. Journal of Social Issues, New York, v. 17, n. 3, p. 45-56, 1961.

CAIRNS, E.; DARBY, J. The conflict in Northern Ireland: causes, consequences, and controls. American Psychologist, Washington, v. 53, p. 754-760, 1988.

CAMPBELL, D. T. Ethnocentric and other altruistic motives. In: LEVINE, D. (Ed.). Nebraska symposium on motivation. Lincoln: University of Nebraska Press, 1965. p. 283-31.

CHRISTIE, D. J. (Ed.). Post-Cold War peace psychology: more differentiated, contextualized, and systemic. Journal of Social Issues, New York, v. 62, n. 1, 2006a. Special issue.

CHRISTIE, D. J. What is peace psychology the psychology of? Journal of social issues, New York, v. 62, n. 1, p. 1-18. 2006b.

CHRISTIE, D. J et al. Peace psychology for a peaceful world. American Psychologist, Washington, v. 63, n. 6, p. 540-552, 2008.

CHRISTIE, D. J. The encyclopedia of peace psychology. New Jersey: John Wiley \& Sons, 2011.

COHRS, J. C.; BOEHNKE, K. Social psychology and peace: an introductory overview. Social psychology, Göttingen, v. 39, n. 1, p. 4-11, 2008.

DANESH, H.B. Towards an integrative theory of peace education. Journal of Peace Education, London, v. 3, n. 1, p. 55-78, 2006.

DAVEL, E.; VERGARA, S. (Org.). Gestão com pessoas e subjetividade. São Paulo: Atlas, 2001.

DEUTSCH, M. William James: The first peace psychologist. Peace and conflict: journal of peace psychology, New Jersey, v. 1, p. 27-36, 1995.

EIDE, E. B. et al. Report on integrated missions: practical perspectives and recommendations: independent study for the expanded UN ECHA core group. [S.I.: s.n.], 2005. 
ERIKSSON, M.; WALLENSTEEN, P.; SOLLENBERG, M. Armed conflict, 1989-2002. Journal of Peace Research, London, v. 40, p. 593-607, 2003.

FONTANELLA, B. J. B, RICAS, J.; TURATO, E. Amostragem por saturação em pesquisas qualitativas em saúde. Caderno de Saúde Pública, Rio de Janeiro, v. 24, n. 1, p. 17-27, 2008.

FERREIRA, A. B. H. Dicionário Aurélio da língua portuguesa. Curitiba: Positivo, 2010.

GALTUNG, J. Peace by peaceful means: peace and conflict, development and civilization. London: Sage, 1996.

GALTUNG, J. Twenty-five years of peace research: ten challenges and some responses. Journal of Peace Research, London, v. 22, p. 141-158, 1985.

GALTUNG, J. Three approaches to peace: peacekeeping, peacemaking and peacebuilding. In: GALTUNG, J. Peace, war and defence: essays in peace research, Copenhagen: Christian Ejlers, 1975. v. 2, p. 282-304.

GALTUNG, J. Violence, peace and peace research. Journal of Peace Research, London, v. 3, p. 176-191, 1969.

GARCIA, A. Biological bases of personal relationships: the contribution of classical Ethology. Revista de Etologia, São Paulo, v. 7, n. 1, 25-38, 2005.

GARCIA, A.; VENTORINI, B. Robert Hinde: da etologia à psicologia social.

In:GARCIA, A.; TOKUMARU, R. S.; BORLOTI, E. B. (Org.). Etologia: uma perspectiva histórica e tendências contemporâneas. Vitória: Multiplicidade, 2005. p. 55-71.

HARE, A. P. The Middle East, Russia and other specific areas. In: BLUMBERG, H. H.; HARE, A. P.; COSTIN, A. (Ed.). Peace psychology: a comprehensive introduction. Cambridge: Cambridge University Press, 2006. p. 32-54.

HINDE, R. A.; FINKENAUER, C.; AUHAGEN, A. E. Relationships and the selfconcept. Personal relationships, London, v. 8, p. 187-204, 2001.

HINDE, R. A.; PARRY, D. (Ed.). Education for peace. Nottingham: Spokesman, 1989.

HINDE, R. A. Relationships: a dialectical perspective. Hove: Psychology Press, 1997.

HINDE, R. A. The psychological bases of war. American diplomacy, [S.I.], 1998. Disponível em: <http://www.unc.edu/depts/diplomat/AD_issues/amdipl_7/ hinde4.htm\#top>. Acesso em: 4 mar. 2011. 
HOLT, R. R.; SILVERSTEIN, B. The image of the enemy: U.S. views of the Soviet Union. Journal of Social Issues, New York, v. 45, n. 2, p. 903-913, 1989. special issue.

JAMES, W. The moral equivalent of war. Peace and conflict: journal of peace psychology, New Jersey, v. 1, p. 17-26,1995.

KANT, I. À paz perpétua. Porto Alegre: L\&PM, 1989.

KELMAN, H. C. International behavior: a social-psychological analysis. New York: Holt, Rinehart \& Winston, 1965.

KNOWLES, P. Servas: 1949-1989, an experiment in peace building. Birmingham: Church Enterprise Print, 1989.

LEDERACH, J. P. Conflict transformation. Intercourse: Good Books, 2003.

LEVINGER, G. Beyond deterrence. Journal of Social Issues, New York, v. 43, n. 4, p. 5-7, 1987. Special issue.

LUMSDEN, M. Breaking the cycle of violence. Journal of peace research, London, v. 34, p. 377-383, 1997.

LUITWEILER, B. Seeds of servas. San Francisco: Richard Piro, 1999.

MINAYO, M. C. S.; DESLANDES, S. F.; GOMES, R. (Org.). Pesquisa social: teoria, método e criatividade. 27. ed. Petrópolis: Vozes, 2010.

MIRANDA. R. F. As mulheres da llha Caieiras: relacionamento interpessoal e cooperação na formação e funcionamento de uma cooperativa. 2009. 245 f. Tese (Doutorado em Psicologia) - Centro de Ciências Humanas e Naturais, Universidade Federal do Espírito Santo, Vitória, 2009.

MOGHADDAM, F. M. The stair case to terrorism: A psychological exploration. American Psychologist, Washington, v. 60, p. 161-169, 2005.

MOGHADDAM, F. M.; MARSELLA, A. J. (Ed.). Understanding terrorism: Psychosocial roots, consequences, and interventions. Washington: American Psychological Association, 2005.

MORAWSKI, J. G.; GOLDSTEIN, S. E. Psychology and nuclear war: a chapter in our legacy of social responsibility. American Psychologist, Washington, v. 40, p. $276-284,1985$.

MULDER, H.; VIGUURS, T. Reinventing hospitality networks: research into the impact of a changing environment on the future of hospitality networks. Rotterdam: Erasmus Universiteit, 2001. 
NAÇÕES UNIDAS. Declaração e Programa de Ação sobre uma Cultura de Paz. Resolução aprovada por Assembleia Geral em 06 de outubro de 1999, n53/243. Original: Declaración y Programa de Acción sobre uma Cultura de Paz. Disponível em: <http://www.onu.org>. Acesso em: 10 set. 2009. NIGEL, Y. (Ed.). The Oxford international encyclopedia of peace. New York: Oxford University Press, 2010.

NJAINE, K.; MINAYO, M. C. de S. A violência na mídia como tema da área da saúde pública: revisão da literatura. Ciência \& Saúde Coletiva, Rio de Janeiro, v. 9, n. 1, p. 201-211, 2004.

OLIVEIRA, A. B. O percurso do conceito de paz: de Kant à atualidade. In: SIMPÓSIO DE RELAÇÕES INTERNACIONAIS DO PROGRAMA DE PÓS-GRADUAÇÃO EM RELAÇÕES INTERNACIONAIS SAN THIAGO DANTAS (UNESP, UNICAMP e PUC-SP), 1. 2007, Londrina. Anais..., Londrina: Universidade Estadual de Londrina, 2007.

ORGANIZAÇÃO MUNDIAL DA SAÚDE. Relatório mundial violência e saúde. Genebra, 2002.

PEREIRA, J. C. Análise de dados qualitativos: estratégias metodológicas para as ciências da saúde, humanas e sociais. 3. ed. São Paulo: Edusp, 2004.

PETTIGREW, T. F. Intergroup contact theory. Annual review psychology, California, v. 49, p. 65-85, 1998.

PILISUK, M. The hidden structure of contemporary violence. Peace and conflict: journal of peace psychology, New Jersey, v. 4, p. 197-216, 1998.

RIVERA, J. H. de. The psychological dimension of foreign policy. Columbus: Charles E. Merrill, 1968.

RUSSELL, R. W. Psychology and policy in a nuclear age. Journal of Social Issues, New York, v. 17, n. 3, p. 1-81, 1961. Special issue.

SANTANA M. S. A violência na mídia e seus reflexos na sociedade. Jus Navigandi, Teresina, ano 8, n. 276, 9 abr. 2004. Disponível em: <http://jus2. uol.com.br/doutrina/texto.asp?id=5062>. Acesso em: 8 out. 2009.

SCHRAIBER, L. B.; D'OLIVEIRA, A. F. P. L.; COUTO, M. T. Violência e saúde: estudos científicos recentes. Revista Saúde Pública, São Paulo, v. 40, p. 112-120, 2006. Disponível em: <http://www.scielo.br/scielo. php? script=sci_arttext\&pid $=$ S0034 $-89102006000400016 \&$ lng $=$ en $\& n r m=i s>$. Acesso em: 10 set. 2009. 
SCHWEBEL, M. Job insecurity as structural violence: Implications for destructive intergroup conflict. Peace and conflict: journal of peace psychology, New Jersey, v. 3, p. 333-351, 1997.

SERVAS handbook. Disponível em: <http://www.servas.org/siexco/index.php/ Servas_Handbook>. Acesso em: 10 set. 2009.

SHERIF, M.; SHERIF, C. W. Groups in harmony and tension: an integration of studies on inter-group relations. New York: Octagon, 1953.

SILVA, B. (Coord.). Dicionário de ciências sociais. Rio de Janeiro: Fundação Getúlio Vargas, 1988.

SIVARD, R. L. World military and social expenditures. Washington: World Priorities, 1996.

SMITH, M. B. Political psychology and peace: A half-century perspective. Peace and conflict: journal of peace psychology, New Jersey, v. 5, n. 1, p. 1-16, 1999.

SMITH, D. N. Psychocultural roots of genocide: legitimacy and crisis in Rwanda. American Psychologist, v. 53, 743-753, 1998.

SOCIETY FOR THE STUDY OF PEACE, CONFLICT, AND VIOLENCE. About the division, [S.I.], [2006]. Disponível em: <http://www.peacepsych.org/about. htm>. Acesso em: 12 set. 2009.

SODRÉ, M.; SOARES, L.; KOSOVSKI, E. (Coord.). Mídia e violência urbana. Rio de Janeiro: FAPERJ, 1994.

SOUZA, L. K et al. Psicologia e paz: a perspectiva de estudantes universitários. Arquivos brasileiros de psicologia, Rio de Janeiro, v. 58, n. 1, p. 12-20, 2006.

SOUZA, L. K. de. É possível uma psicologia para a paz?: apresentando a peace psychology. Psico, Porto Alegre, v. 34,n. 1, p. 39-56, 2003.

STRAUS, A. E.; CORBIN, J. Pesquisa qualitativa: técnicas e procedimentos para o desenvolvimento de teoria fundamentada. 2. ed. Porto Alegre: Artmed, 2009.

UNESCO. Second medium-term plan, 1984-1989. Paris, 1983. Disponível em: <http://unesdoc.unesco.org/images/0005/000546/054611eb.pdf>. Acesso em: 28 mar. 2008.

VENTORINI, B.; GARCIA, A. Relacionamento interpessoal: da obra de Robert Hindeà gestão de pessoas. Revista Psicologia: organizações e trabalho, Brasília, DF, v. 4, n. 2, p. 117-143, 2004. 
VERGARA, S. C. Projetos e relatórios de pesquisa em administração. 7. ed. São Paulo: Atlas, 2006.

VOLLHARDT, J.; BILALI, R. Social psychology's contribution to the psychological study of peace. Social Psychology, Washington, v. 39, n. 1, p. 12-25, 2008.

WAGNER, R. V. Psychology and the threat of nuclear war. American Psychologist,Washington, v. 40, p. 531-535, 1985.

WAGNER, R. V. Distinguishing between positive and negative approaches to peace. Journal of Social Issues, New York, v. 44, n. 2, p. 1-15, 1988.

WAGNER, R. V. September 11, 2001: how can peace psychologists be most helpful? Peace and conflict: journal of peace psychology, New Jersey, v. 8, p. 183-186, 2002.

WAGNER, R. V. Terrorism: a peace psychological analysis. Journal of Social Issues, New York, v. 62, n. 1, p. 155-171, 2006.

WAGNER, R. V.; DE RIVERA, J.; WATKINS, M. (Ed.). Psychology and the promotion of peace. Journal of Social Issues, New York, v. 44, n. 2, 1988. Special issue.

WALSH, R. Staying alive: the psychology of human survival. Boulder: Shambala, 1984.

WESSELLS, M. G. A history of division 48 (Peace Psychology). In: DEWSBURY, D. A. (Ed.). Unification through division: histories of the divisions of the American Psychological Association. Washington: American Psychological Association, 1996. p. 265-298. v. 1.

WESSELLS, M. G. Systemic approaches to the understanding and prevention of genocide and mass killing. peace and conflict: journal of peace psychology, New Jersey, v. 5, n. 4, p. 365-371, 1999.

WHITE, R. K. Misperception and the Vietnam War. Ann Arbor: society for the psychological study of social issues, 1986a.

WHITE, R. K. Psychology and the prevention of nuclear war. New York: New York University Press, 1986b. 